(C) The Authors 2017. This is an Open Access article, distributed under the terms of the Creative

Commons Attribution licence (http://creativecommons.org/licenses/by/4.0/), which permits unrestricted

re-use, distribution, and reproduction in any medium, provided the original work is properly cited.

\title{
Decreased, but still sufficient, iodine intake of children and adults in the Netherlands
}

\author{
Janneke Verkaik-Kloosterman*, Elly J. M. Buurma-Rethans, Arnold L. M. Dekkers \\ and Caroline T. M. van Rossum \\ National Institute for Public Health and the Environment (RIVM), PO Box 1, 3270 BA Bilthoven, The Netherlands
}

(Submitted 1 December 2016 - Final revision received 2 February 2017 - Accepted 2 March 2017)

\section{Abstract}

Sufficient I intake is important for the synthesis of thyroid hormones, which play an important role in normal growth and development. Our aim was to estimate habitual I intake for the Dutch population and the risk of inadequate or excessive intakes. Further, we aimed to provide an insight into the dietary sources of I and the association with socio-demographic factors. Data from the Dutch National Food Consumption Survey 2007-2010 ( $n$ 3819; 7-69 years), and from the Dutch food and supplement composition tables were used to estimate habitual I intake with a calculation model. Contribution of food groups to I intake were computed and multiple linear regression was used to examine associations of intakes with socio-demographic factors. A total of $\leq 2 \%$ of the population had an intake below the estimated average requirement or above the upper level. The main sources of I were bread containing iodised salt (39\%), dairy products (14\%) and nonalcoholic drinks (6\%). I intake (natural sources only, excluding iodised salt and supplements) was positively associated with (parental) education, which could at least partly be attributed to a higher consumption of dairy products. Among children, the consumption of bread, often containing iodised bakery salt, was positively associated with parental education. The I intake of the Dutch population (7-69 years) seems adequate, although it has decreased since the period before 2008 . With the current effort to reduce salt intake and changing dietary patterns (i.e. less bread, more organic foods) it is important to keep a close track on the I status, important sources and potential risk groups.

Key words: Iodine: Dietary sources: Adults: Children: Habitual intake

I is an essential element for efficient functioning of the thyroid gland and the synthesis of thyroid hormones. These hormones play an important role in the early growth and development of several organs, especially the brain; further, they regulate metabolic processes. Inadequate I intake results in I deficiency disorders, with goitre as a well-known clinical sign. In addition, I deficiency during early childhood, including pregnancy, results in impaired brain development and consequently, reduced mental functioning ${ }^{(1)}$. Besides harmful effects of too low I intakes, excessive intakes cause biochemical changes such as elevated thyroxin and decreased thyroid stimulating hormone concentrations. It is, however, uncertain if clinical health effects would appear because of chronic exposure to these biochemical changes ${ }^{(2)}$.

In many countries, including the Netherlands, the natural I levels of foods are not adequate. Therefore, worldwide, I fortification and supplementation programmes are implemented $^{(1)}$. Nevertheless, in many countries including Europe, (mild/moderate) I deficiency remains a public health problem ${ }^{(3)}$. The Netherlands has a long history of salt iodisation programmes starting in 1928 (Box 1), and is considered to be one of the countries with adequate I intakes ${ }^{(1,4,13)}$.

The national I policy changed several times in the Netherlands, to create or maintain the population's adequate I intake, to prevent excessive intake and to meet European legislation (Box 1). The most recent change is from $2008^{(10)}$. Before 2008, the addition of iodised salt was limited to specific food groups (bread, household salt, bread-replacing products, meat products) at specified levels (bread salt $70-85 \mathrm{mg} \mathrm{I} / \mathrm{kg}$ salt; household salt 30-40 mg I/kg salt; meat products $20-30 \mathrm{mg} \mathrm{I} / \mathrm{kg}$ salt). For all these food groups, the addition of iodised salt was on a voluntary basis; however, there is a covenant between the Ministry of Health and the bakery sector to use iodised bread salt for bread (because of a court decision (Box 1) organic bread is excluded from this covenant, although iodised bread salt may voluntary be added to organic bread). Since 2008, iodised bakery salt (a maximum of $65 \mathrm{mg} \mathrm{I} / \mathrm{kg}$ salt) may be added to bread and all bakery products, still on a voluntary basis. For all other food, iodised salt with a maximum of $25 \mathrm{mg} \mathrm{I} / \mathrm{kg}$ salt may be used. With the change of the I policy,

Abbreviations: DNFCS, Dutch National Food Consumption Survey; EAR, estimated average requirement; SPADE, Statistical Program to Assess Dietary Exposure; UL, tolerable upper intake level.

* Corresponding author: J. Verkaik-Kloosterman, email Janneke.Verkaik@RIVM.nl 
Box 1. Historic overview of iodisation programmes in the Netherlands ${ }^{(4-12)}$

Years Event

1928 Introduction iodised kitchen salt, mainly used on medical advice

1932 Regional iodisation of drinking water $(50 \mu \mathrm{g} \mathrm{KI} / \mathrm{l})$; because of introduction of tap water, an increase in goitre in some regions

1942 Introduction of iodised bread salt (31 mg I/kg salt) and stop of regional iodisation of drinking water

1960 Start of mandatory iodisation of bread salt $(39 \mathrm{mg} \mathrm{KI} / \mathrm{kg}$ salt $)$ in regions with low water I concentration $(<40 \mu \mathrm{g} / \mathrm{l})$

1968 Mandatory iodisation of bread salt ( $46 \mathrm{mg} \mathrm{KI} / \mathrm{kg}$ salt) across the whole country: 'Broodbesluit'

1974 Iodised kitchen salt no longer available

1982 I level in bread salt increased to $60 \mathrm{mg} \mathrm{KI} / \mathrm{kg}$ and reintroduction of iodised kitchen salt (23-29 mg KI/kg): 'Zoutbesluit'

1984 Court decision: mandatory iodisation of bread salt replaced by voluntary addition regulated via a covenant between the

Minister of Health and the (industrial) bakeries

1985 I level in bread salt revised to $55-65 \mathrm{mg} \mathrm{KI} / \mathrm{kg}$

1998 New legislation: addition of I to foods is prohibited except for bread salt (55-65 mg KI/ $\mathrm{kg}$ salt) and kitchen salt (45-55 $\mathrm{mg} \mathrm{KI} / \mathrm{kg})$

1999 Revision I legislation: kitchen salt 30-40 mg KI/ $/ \mathrm{kg}$, bread salt 70-85 mg KI/ kg, nitrate grid salt in meat products 30-40 mg KI/kg

2004 Arrest EU court: bread with lower I levels permitted, otherwise a trade barrier

2008 Revision I legislation: bakery salt (for all bakery products) maximum $65 \mathrm{mg} \mathrm{KI} / \mathrm{kg}$, salt for other products (including kitchen salt) maximum $25 \mathrm{mg} \mathrm{KI} / \mathrm{kg}$

it was expected that $50 \%$ of the foods other than bread would contain iodised salt ${ }^{(14)}$. Because of the covenant between the Ministry of Health and the bakery sector, almost all bread contains iodised bakery salt ${ }^{(5)}$.

The I status was measured in 2006 and 2010 in a cohort in the Netherlands. Estimates of the I intake from non-replicated 24-h urine samples showed a decrease in I intake; in 2010 the median intake was $179 v .262 \mu \mathrm{g} / \mathrm{d}$ in $2006^{(13)}$. In spite of the change in the Dutch I policy, a decrease in I intake was not anticipated. Although measurement of repeated 24-h urinary I excretion in combination with statistical correction for withinperson variation is the best way to get an insight into the habitual I intake and status ${ }^{(15-17)}$, such data do not provide information on major I sources in the population's diet and does not give the opportunity to estimate the effects of changing I and/or salt policies on the intake. Earlier, VerkaikKloosterman et al. ${ }^{(18,19)}$ developed a model to estimate the habitual I intake from food consumption survey data collected with two repeated 24-h recalls per subject. The aims of the present study were to assess the adequacy and safety of I intake in the Dutch population, to get an insight into the main sources of $\mathrm{I}$ in the Dutch diet and understand the socio-demographic factors affecting the I intake. An insight into socio-demographic factors associated with I intake can be used to improve interventions or I policy. With a slightly adapted version of this model, the habitual I intake was estimated for the Dutch population using data from the most recent Dutch National Food Consumption Survey (DNFCS) 2007-2010 and data from the Dutch food and supplement composition tables. The adequacy and safety of I intake in the Netherlands was evaluated by estimation of the proportion of the population with intakes below the estimated average requirement (EAR) set by the Institute of Medicine ${ }^{(20)}$ or above the Tolerable upper intake level (UL) set by the Scientific Committee on Food $(\mathrm{SCF})^{(2)}$.

\section{Methods}

\section{Survey population}

Data from the DNFCS 2007-2010 were used, in which the dietary intake was estimated from two non-consecutive 24-h recalls. Details of this representative cross-sectional study are described elsewhere ${ }^{(21)}$; in brief, subjects were drawn from representative consumer panels of Market Research GfK Panel Services. Data were collected among Dutch children and adults aged 7-69 years (study sample $n$ 3819; net response rate $69 \%$ ); pregnant and lactating women as well as institutionalised people were excluded. The sampling was guided by socio-demographic characteristics and stratified by age and sex. The distribution of levels of education, region and urbanisation in the study population were close to the general Dutch population. Days of the week and seasons were almost equally spread, with a small overrepresentation of winter, and Tuesdays and Thursdays at the expense of Saturdays. For the small deviations of the survey population from the Dutch population, a weighing factor was created based on socio-demographic characteristics, season and day of the week. Using this weighing factor, the results can be considered representative for the Dutch population over a calendar year. This weighting factor was applied in all statistical analyses. Unless otherwise stated, all analyses were performed with SAS 9.2 (SAS Institute Inc.). The study was conducted according to the guidelines of the Helsinki Declaration.

\section{Dietary assessment}

Detailed information on food and dietary supplement consumption was collected by trained dietitians using the computer-assisted 24-h recall method - GloboDiet (formerly EPIC-Soft ${ }^{\circledR}$ of the International Agency for Research on Cancer). All subjects were interviewed on 2 non-consecutive days 


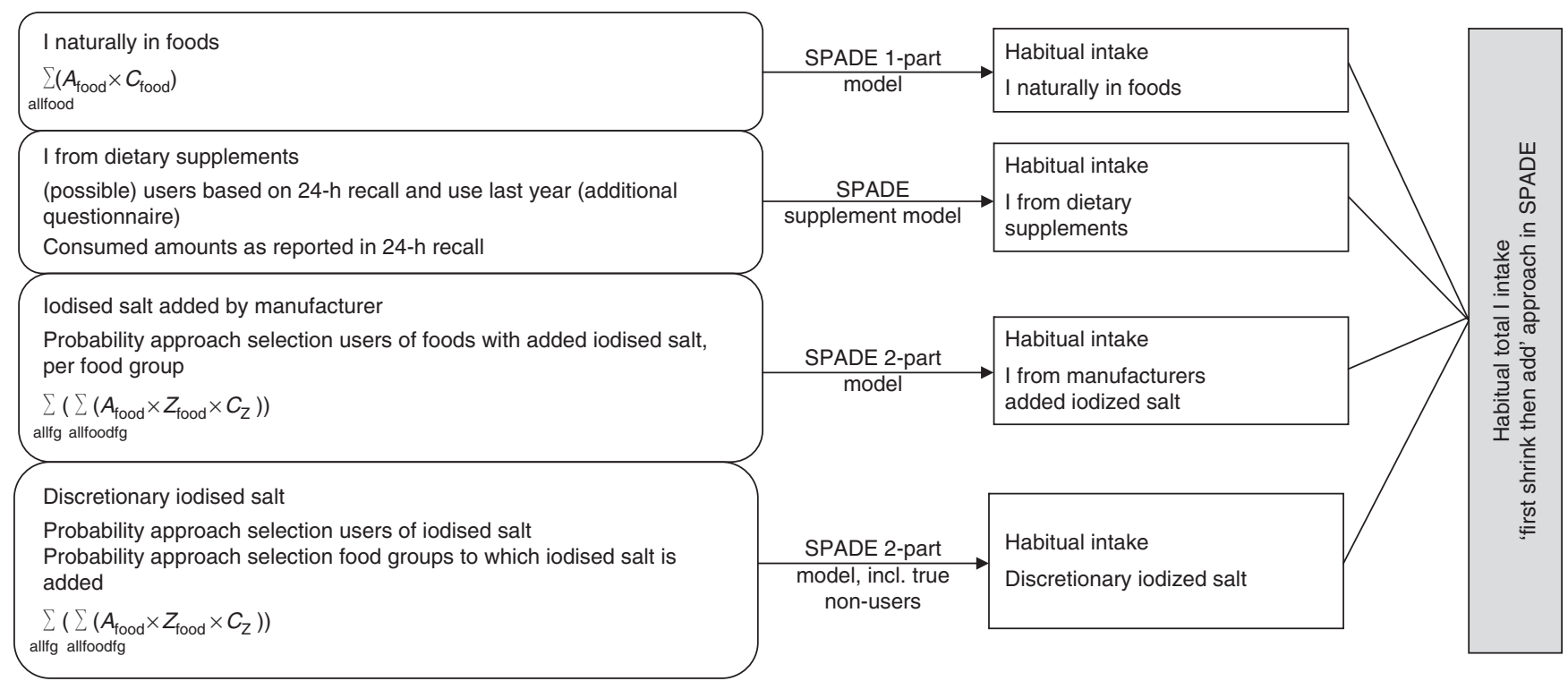

Fig. 1. Schematic overview of the mathematical model to estimate the habitual total iodine intake distribution. Food, consumed food; $A_{\text {food, }}$ consumed amount of a food; $C_{\text {food, }}$ iodine concentration in a food; fg, food group; $C_{\mathrm{z}}$, iodine concentration in salt; $Z_{\text {food, }}$, salt (added sodium) concentration in a food; SPADE, Statistical Program to Assess Dietary Exposure

(2-6 weeks apart). Children aged 7-15 years were interviewed face-to-face during (appointed) home visits in presence of the parent/caretaker. Persons aged $\geq 16$ years were interviewed by telephone at unannounced dates and times. Interviews were not planned on national and/or religious holidays, or when the participant was on holiday. In addition to the 24-h recalls, lifestyle characteristics were collected with a general questionnaire, including general characteristics of the dietary pattern and the consumption of specific foods and supplements. Height and weight were self-reported by the subjects.

The I concentration naturally present in foods were taken from the Dutch Food Composition Database (NEVOonline 2011/3.0) ${ }^{(22)}$. This database contains information of more than 2000 foods, preferably from chemical analyses, supplemented with information collected from foreign food composition tables, scientific literature and food labels. The source of each composition value is known and can be found in NEVO-online. For the composition of supplements, the Dutch Supplement Database of 1 January 2008 (NES) was used $^{(23)}$.

\section{Estimation total habitual iodine intake distribution}

The total I intake can be divided into four main sources, namely:

(a) I naturally present in food (excluding iodised salt and supplements);

(b) iodised salt used by food manufacturers;

(c) iodised salt used during meal preparation and consumption; and

(d) dietary supplements.

We used an adapted version of the model described by Verkaik-Kloosterman et al. ${ }^{(18,19)}$. In short, the habitual I intake distribution was estimated separately, using an age-dependent model, for each of the four main sources; thereafter, these four distributions were combined using Monte Carlo simulation to get the total habitual I intake distribution (Fig. 1). Habitual intake was defined as the long-time average intake of an individual and was estimated using the Statistical Program to Assess Dietary Exposure (SPADE version 3.1 of 27 November $2015)^{(26)}$. On the basis of 2 independent survey d per subject, the data can be corrected for the within-person variation to get the population's habitual intake distribution.

(a) lodine naturally present in food (excluding iodised salt and supplements). The intake of I naturally present in foods (excluding iodised salt and supplements) (a) was estimated by combining the food consumption data with the food composition data, resulting in the I intake per food item (NEVO-code) per subject per survey day. To estimate the contribution of several food groups to the intake of I naturally present in foods, the mean intake over 2 survey d was estimated for each subject. Per food group, the distribution of the proportion of intake of I naturally present in foods was calculated. Bread and other foods known to be produced with iodised salt were not included in this category, but taken into account in the category (b) iodised salt used by food manufacturers. The habitual intake distribution was estimated.

(b) and (c) lodised salt added during processing or during meal preparation and consumption. Detailed information on the discretionary use of iodised salt (c) and the application of iodised salt by food manufacturers (b) is lacking; therefore, the total I intake was estimated using a probabilistic calculation model, in order to quantify the uncertainty. From the survey population ( $n$ 100; Monte Carlo sampling), samples were repeatedly drawn (stratified by age and sex) to assign a 
subject as discretionary user of salt. From each of these samples, an additional sample was drawn to assign discretionary users of salt to the use of iodised salt. A similar procedure was applied for the estimation of I intake from iodised salt added by food manufacturers; however, the sampling ( $n$ 100; Monte Carlo sampling) was performed among consumers of specific food groups (Table 1), instead of the whole population. Samples were drawn separately for different foods or food groups, and selected subjects were assigned to consume foods from that specific food group containing iodised salt. The proportion of subjects drawn was equal to the proportions presented in Table 1. This resulted in 100 distributions of I intake from discretionarily added iodised salt as well as iodised salt added by the food manufacturer. The differences between these 100 distributions were taken to represent the uncertainty in estimation of the I intake from these main sources. The habitual intake distribution was estimated with SPADE for each of these 100 samplings, resulting in 100 habitual intake distributions for the discretionarily added I intake as well as the intake of I from iodised salt added by manufacturers. For I intake from iodised salt added by manufacturers a SPADE 2-part model $^{(24)}$ was applied, as a part of the consumers of the selected foods were selected to have consumed products without added iodised salt, resulting in a zero intake from this source. For discretionarily added I, the habitual intake was estimated with a SPADE 2-part model taking into account true non-consumers ${ }^{(24)}$ of this source, that is, subjects never adding salt to their food during meal preparation or consumption.

(d) Dietary supplements. In DNFCS, potential users of I-containing dietary supplements were defined as follows: subjects who reported intake of I from dietary supplements in at least one of the 24-h recalls and/or subjects who reported use of supplement categories that may contain I in the frequency questionnaire. Consequently, for some subjects no amount information was available (user according to frequency questionnaire, but no intake in 24-h recalls). For subjects with a known amount of I intake from dietary supplements, these amounts were set as the habitual intake amount, as described by Dekkers et al. For the remaining subjects having no I intake from dietary supplements on the recall days, the habitual intake amount was predicted with a regression tree model ${ }^{(24)}$. The SPADE supplement model was used to estimate the habitual I intake from dietary supplements ${ }^{(24)}$.

\section{Assumptions for iodine intake from iodised salt}

As stated above, detailed information on the use of iodised salt is lacking; therefore, additional information was gathered as input in the probabilistic approach. In the 3rd year of data collection of DNFCS 2007-2010 the additional questionnaire was expanded with questions on the use of (iodised) salt during meal preparation and consumption. From this information, the proportion of subjects that answered to never use discretionarily (iodised) salt was calculated (stratified by age and sex) (Table 1). These proportions were used for the sampling of
Table 1. Overview of assumptions in the calculation model to estimate habitual total iodine intake in the Dutch population based on data from the Dutch National Food Consumption Survey (DNFCS) 2007-2010

\begin{tabular}{|c|c|c|}
\hline \multirow[b]{2}{*}{ Descriptions } & \multicolumn{2}{|c|}{ Assumption } \\
\hline & $\begin{array}{l}\text { Proportion with no } \\
\text { salt use (\%) }\end{array}$ & $\begin{array}{l}\text { If salt; proportion with no } \\
\text { iodised salt (\%) }\end{array}$ \\
\hline \multirow{4}{*}{\multicolumn{3}{|c|}{$\begin{array}{l}\text { Reported discretionary } \\
\text { use of (iodised) salt* } \\
\text { Age group (years) } \\
7-8\end{array}$}} \\
\hline & & \\
\hline & & \\
\hline & & \\
\hline Males & 16 & 9 \\
\hline Females & 15 & 15 \\
\hline \multicolumn{3}{|l|}{$9-13$} \\
\hline Males & 7 & 9 \\
\hline Females & 16 & 15 \\
\hline \multicolumn{3}{|l|}{$14-18$} \\
\hline Males & 5 & 8 \\
\hline Females & 8 & 10 \\
\hline \multicolumn{3}{|l|}{$19-30$} \\
\hline Males & 13 & 11 \\
\hline Females & 14 & 11 \\
\hline \multicolumn{3}{|l|}{$31-50$} \\
\hline Males & 9 & 21 \\
\hline Females & 16 & 19 \\
\hline \multicolumn{3}{|l|}{$51-69$} \\
\hline Males & 17 & 8 \\
\hline Females & 17 & 6 \\
\hline Discretionary use of salt & Proportion (\%) & $\mathrm{g}$ salt/100 g \\
\hline \multicolumn{3}{|l|}{ Food group } \\
\hline Potatoes & 85 & 0.4 \\
\hline Mashed potatoes & 85 & 0.6 \\
\hline Rice and pasta & 85 & 0.4 \\
\hline Vegetables & 75 & 0.6 \\
\hline Meat & 95 & 1.8 \\
\hline Fish & 95 & $1 \cdot 8$ \\
\hline Meat replacers & 95 & 1.8 \\
\hline Eggs & 75 & 1.8 \\
\hline Homemade sauces & 80 & 0.8 \\
\hline Pancakes & 80 & 0.2 \\
\hline Use of iodised salt by & Proportion (\%) & Low/high iodised salt§ \\
\hline \multicolumn{3}{|l|}{ Product group } \\
\hline Bread & 95 & High \\
\hline Pizza & 40 & Low \\
\hline Pastry and cookies & 1 & High \\
\hline Dutch rusk & 0.5 & Low \\
\hline Crackers & 0.5 & Low \\
\hline (Sliced) cold meat & 0.5 & Low \\
\hline \multicolumn{3}{|c|}{$\begin{array}{l}\text { * Calculated from data of 3rd year of data collection DNFCS } 2007-2010 . \\
\dagger \text { Foods containing salt added by manufacturers were excluded. } \\
\text { † For branded foods with known use of iodised salt a deterministic approach was } \\
\text { applied. Baking mix, chips for children, dressing and sausage rolls are available } \\
\text { with iodised salt; however, the number of users in DNFCS } 2007-2010 \text { was }<100 \text {; } \\
\text { using a market share of } 0.5 \% \text {, this would result in }<1 \text { person; these products were } \\
\text { considered as never containing iodised salt. }\end{array}$} \\
\hline
\end{tabular}

subjects in the 1st and 2nd years of data collection. Per age and sex category, a sample as large as the proportion was drawn for 100 iterations. The selected subjects were assigned to not discretionarily adding (iodised) salt. The remaining subjects were assigned to discretionarily adding (iodised) salt. For the 3rd year of data collection, a deterministic approach was applied using the subject-specific information directly. 
The discretionary use of (iodised) salt varies among food groups $^{(25)}$ (D van der Zee, unpublished results, Dutch Bakery Center (NBC), 16 September 2011). In the current calculation model, it was therefore not assumed that subjects discretionarily adding (iodised) salt would do this always for all food groups they consumed, in contrast with the earlier calculation model $^{(18,19)}$. Unfortunately, there are no data available on the discretionary use of (iodised) salt for different food groups that distinguish between foods produced with and those produced without salt. In the calculation model, foods produced with salt were not selected for discretionary addition of salt either. On the basis of the proportions of subjects using (iodised) salt in the 3rd year of data collection in DNFCS 2007-2010 and the very limited information on differences in salt use between food groups ${ }^{(25)}$ (D van der Zee, unpublished results, NBC, 16 September 2011), the authors made an assumption for the proportion of subjects discretionarily adding salt to the food groups potatoes, rice and pasta, vegetables, meat and meat replacers, eggs, fish, homemade sauces and pancakes (Table 1). The amount of salt discretionarily added was taken from VerkaikKloosterman et al. ${ }^{(18,19)}$. In these studies, the amount of salt added per $100 \mathrm{~g}$ food was estimated on the basis of cookbook recipes and guidelines of the Dutch Food Consumption Table.

There is no up-to-date information on the use of iodised salt by Dutch food manufacturers. For our study the Federation of Dutch grocery and food industry (FNLI) and the Dutch Bakery Association (NVB) have sent a questionnaire to all their members to find out how often iodised salt was used. Most of the fresh bread was prepared with iodised bakery salt, as well as about half of the partially baked bread segment (WM van Andel (NVB) and C Grit (FNLI), unpublished results, 8 December 2011). On the basis of market shares and the fact that part of the organic bread is prepared with non-iodised sea salt, it was assumed that $95 \%$ of the consumed bread contained iodised salt. In addition, several specific brands of breakfast crackers and gingerbreads contained iodised salt. As these foods were present in NEVO with a specific NEVO-code, the I content was added to this code. Also two big pizza brands, having a market share of about $40 \%$, use iodised salt. Salt (Na) in pizza originates from many different sources, for example, the dough, the various toppings, the cheese. Not all the Na in pizza is from added salt; in addition, not all different parts of the pizza may be processed with iodised salt; therefore, it was assumed by the authors that, on average, $50 \%$ of the salt in pizza is from added iodised salt. Besides this questionnaire, the INNOVA database (www.innovadatabase.com) was searched for foods available in the Netherlands containing iodised salt as an ingredient. This showed that foods imported mainly from Germany contain iodised salt. In addition, it showed that foods produced with iodised salt are available in many different food groups, however the proportion within each food group is in general limited. On the basis of this information, the market shares were assumed to be $0 \cdot 5-1 \%$. In DNFCS 2007-2010, the number of consumers was limited for some of these products containing iodised salt $(n<100)$, such as bakery mixtures, chips, sausage rolls and dressing. In combination with the low market shares containing iodised salt, these food groups were assumed to be all prepared without iodised salt. For the remaining food groups, a market share of $0.5 \%$ was taken for meat products, Dutch rusk, other breakfast crackers, and $1 \%$ was taken for cookies, cakes and sweet pies (Table 1).

The Dutch salt industry aims at an average I concentration of $20 \mathrm{mg} / \mathrm{kg}$ salt (low I salt) and for bakery salt an average of $58 \mathrm{mg} / \mathrm{kg}$ salt ${ }^{(19)}$. These concentrations were applied in our study.

\section{Dietary reference intakes for iodine}

There are no national recommendations for I intake in the Netherlands. For this study, we used the US Institute of Medicine (currently Health and Medicine Division of the National Academies of Sciences, Engineering and Medicine) dietary reference values for I to evaluate the adequacy of I intake ${ }^{(20)}$. The EAR cutoff point method was used to estimate the proportion of the population with inadequate I intakes. The SCF (predecessor of the European Food and Safety Authority) has set a UL for I; these were used to estimate the proportion of the population with intakes above the $\mathrm{UL}^{(2)}$.

\section{Population characteristics}

I intake can vary between population groups. The observed I intake from natural sources (excluding iodised salt and supplements) was estimated for several population characteristics (age, sex, BMI, income of the head of the household, education (for children, highest education of parents), season, region) using Proc SurveyMeans (SAS 9.2). With linear regression (Proc SurveyReg (SAS 9.2); $P<0.05$ statistically significant) it was studied how the intake of I naturally present in foods and population characteristics were associated, similar to Huybrechts et al. ${ }^{(26)}$. These analyses were performed separately for children (7-18 years) and adults (19-69 years). The variables I intake and I intake $/ 418 \mathrm{~kJ}$ (100 kcal) were natural log transformed to improve normality of the data and residuals. Potential outliers were detected and analyses were performed including and excluding these outliers to study the impact on the results. Linear regression was also performed to study the association between the intake of two food groups (milk and cheese) contributing most to the intake of I naturally present in foods (excluding iodised salt and supplements) and to the intake of bread (a main source of iodised salt), among consumers only. These intake variables were square root transformed to improve normality of the data and residuals, except for cheese intake among adults that was transformed with a natural log.

\section{Results}

\section{Characteristics of the study population}

The total study sample of 3819 subjects included 1713 children aged 7-18 years and 2106 adults (19-69 years) (Table 2). Compared with the Dutch population distribution, children were overrepresented and adults were underrepresented in the sample; however, with weighting for socio-demographic factors, this was corrected. In all, $>40 \%$ of the subjects originated from the western region, about 
$10 \%$ from Northern Netherlands and 20-25\% from the East and the South; this represented the Netherlands well. The seasons were more or less equally distributed over the 1st recall days.

\section{Habitual iodine intake}

The habitual I intake from natural sources only (excluding iodised salt and supplements) was, as expected, inadequate for most of the population (Table 3). For females aged 7-69 years, $84 \%$ had an intake below their age-specific EAR; for males this was $67 \%$. For both males and females, the proportions were highest for adolescents and young adults (15-30 years).

In general, the habitual total I intake was higher for males compared with females and increased with age for both males and females, except men aged 51-69 years for whom the habitual intake was lower compared with men aged 31-50 years. (Table 4). For males, the median habitual total I intake ranged from 161 to $248 \mu \mathrm{g} / \mathrm{d}$, for females the range of medians was $150-199 \mu \mathrm{g} / \mathrm{d}$. The proportion with intakes below the EAR was $0-2 \%$ in the different age groups and was slightly more frequent among females. Among females and adolescent and adult men the intake did not exceed the UL; for boys, 1-2\% had an intake above the UL (Table 4).

\section{Sources of iodine}

On average, $40 \%$ of the I intake came from I naturally present in food, $43 \%$ came from iodised salt added by the food manufacturer, of which about $90 \%$ could be contributed by bread prepared with iodised bakery salt. Discretionarily added iodised salt and supplements had an average contribution to the total I intake of 14 and $3 \%$, respectively (Fig. 2).

On average, the main sources of I naturally present in foods were dairy products (32\%), non-alcoholic drinks (14\%), cereals and cereal products ( $8 \%$ ), and meat and meat products (7\%) (Fig. 2). The contribution of the food groups was similar between children and adults, although children had a somewhat higher contribution from dairy products compared with adults (online Supplementary Table S1). Adult women had a slightly higher contribution from supplements. In the group of dairy products, milk (average 37-52\%) had the highest contribution to I intake for both children and adults followed by cheese (12-21\%) and yogurt (15-20\%), and also by

Table 2. Characteristics of the subjects participating in the Dutch National Food Consumption Survey 2007-2010 (Numbers and percentages)

\begin{tabular}{|c|c|c|c|c|c|c|c|c|}
\hline \multirow[b]{3}{*}{ Characteristics* $^{*}$} & \multicolumn{4}{|c|}{ Children (7-18 years) } & \multicolumn{4}{|c|}{ Adults (19-69 years) } \\
\hline & \multirow[b]{2}{*}{$n$} & \multirow[b]{2}{*}{$\%$} & \multicolumn{2}{|c|}{ Weighted $\dagger$} & \multirow[b]{2}{*}{$n$} & \multirow[b]{2}{*}{$\%$} & \multicolumn{2}{|c|}{ Weighted $†$} \\
\hline & & & $n$ & $\%$ & & & $n$ & $\%$ \\
\hline$n$ & \multicolumn{2}{|c|}{1713} & \multicolumn{2}{|c|}{685} & \multicolumn{2}{|c|}{2106} & \multicolumn{2}{|c|}{3134} \\
\hline \multicolumn{9}{|l|}{ Age-sex } \\
\hline Boys (7-8 years)/men (19-30 years) & 153 & 8.9 & 60 & $8 \cdot 7$ & 356 & $16 \cdot 9$ & 339 & $10 \cdot 8$ \\
\hline Girls (7-8 years)/women (19-30 years) & 151 & $8 \cdot 8$ & 57 & 8.4 & 347 & $16 \cdot 5$ & 335 & $10 \cdot 7$ \\
\hline Boys (9-13 years)/men (31-50 years) & 351 & $20 \cdot 5$ & 144 & $21 \cdot 0$ & 348 & $16 \cdot 5$ & 703 & $22 \cdot 4$ \\
\hline Girls (9-13 years)/women ( $31-50$ years) & 352 & $20 \cdot 6$ & 137 & $20 \cdot 0$ & 351 & $16 \cdot 7$ & 696 & $22 \cdot 2$ \\
\hline Boys (14-18 years)/men (51-69 years) & 352 & $20 \cdot 6$ & 147 & 21.4 & 351 & $16 \cdot 7$ & 531 & $16 \cdot 9$ \\
\hline Girls (14-18 years)/women (51-69 years) & 354 & $20 \cdot 7$ & 140 & $21 \cdot 0$ & 353 & $16 \cdot 8$ & 530 & $16 \cdot 9$ \\
\hline \multicolumn{9}{|l|}{ Region } \\
\hline West & 736 & $43 \cdot 0$ & 295 & $43 \cdot 0$ & 935 & $44 \cdot 4$ & 1401 & 44.7 \\
\hline North & 180 & 10.5 & 72 & 10.5 & 218 & $10 \cdot 4$ & 325 & $10 \cdot 4$ \\
\hline East & 379 & $22 \cdot 1$ & 155 & $22 \cdot 7$ & 446 & $21 \cdot 2$ & 657 & $21 \cdot 0$ \\
\hline South & 418 & $24 \cdot 4$ & 164 & $23 \cdot 9$ & 507 & $24 \cdot 1$ & 751 & $24 \cdot 0$ \\
\hline \multicolumn{9}{|l|}{ Season (1st recall day) } \\
\hline Spring & 388 & $22 \cdot 7$ & 171 & $25 \cdot 0$ & 489 & 23.2 & 783 & $25 \cdot 0$ \\
\hline Summer & 410 & 23.9 & 171 & $25 \cdot 0$ & 509 & $24 \cdot 2$ & 783 & $25 \cdot 0$ \\
\hline Autumn & 433 & $25 \cdot 3$ & 171 & $25 \cdot 0$ & 517 & $24 \cdot 6$ & 784 & $25 \cdot 0$ \\
\hline Winter & 482 & $28 \cdot 1$ & 171 & $25 \cdot 0$ & 591 & $28 \cdot 1$ & 783 & $25 \cdot 0$ \\
\hline \multicolumn{9}{|l|}{ Educational level } \\
\hline Low & 373 & $22 \cdot 1$ & 148 & 21.9 & 709 & 33.7 & 1007 & $32 \cdot 1$ \\
\hline Middle & 725 & $42 \cdot 9$ & 294 & 43.5 & 935 & 44.4 & 136 & $7 \cdot 6$ \\
\hline High & 591 & $35 \cdot 0$ & 233 & 34.6 & 462 & $21 \cdot 9$ & 761 & $24 \cdot 3$ \\
\hline \multicolumn{9}{|l|}{ Income head of house hold } \\
\hline$<$ Modal & 634 & $37 \cdot 0$ & 256 & $37 \cdot 3$ & 779 & $37 \cdot 0$ & 1125 & 35.9 \\
\hline Modal-2x modal & 974 & $56 \cdot 9$ & 390 & $56 \cdot 9$ & 1168 & 55.5 & 1747 & 55.8 \\
\hline$>2 \times$ modal & 105 & $6 \cdot 1$ & 40 & $5 \cdot 8$ & 159 & $7 \cdot 6$ & 261 & $8 \cdot 3$ \\
\hline \multicolumn{9}{|l|}{ BMI } \\
\hline Underweight & 156 & $9 \cdot 1$ & 63 & 9.3 & 48 & $2 \cdot 3$ & 56 & 1.8 \\
\hline Normal weight & 1248 & $72 \cdot 9$ & 499 & $72 \cdot 9$ & 962 & $45 \cdot 7$ & 1370 & $43 \cdot 8$ \\
\hline Overweight & 308 & $18 \cdot 0$ & 122 & $17 \cdot 8$ & 1095 & $52 \cdot 0$ & 1706 & 54.5 \\
\hline
\end{tabular}

* BMI based on average height and weight (self-reported), categories based on ${ }^{(9,11,12)}$; education: low $=$ primary school, lower vocational, low or intermediate general education; middle = intermediate vocational education and higher general education; high =higher vocational education and university; region west includes the three main cities of the Netherlands; modal income in $2010=32500 €$ gross wage/year ${ }^{(48)}$.

† Weighted for socio-demographic factors to make samples representative of the Dutch population. 
Table 3. Estimated habitual total iodine intake from natural sources (excluding iodised salt and supplements) for Dutch men and women in several age categories and the proportion with a habitual intake below the estimated average requirement (EAR)

(5th, 25th, 75th and 95th percentiles and medians)

\begin{tabular}{|c|c|c|c|c|c|c|c|c|}
\hline & \multirow[b]{2}{*}{$n$} & \multicolumn{5}{|c|}{ Habitual total I intake from natural sources $(\mu \mathrm{g} / \mathrm{d})$} & \multirow[b]{2}{*}{ EAR } & \multirow[b]{2}{*}{$\%<$ EAR } \\
\hline & & P5 & P25 & Median & P75 & P95 & & \\
\hline All men (7-69 years) & 1911 & 50 & 67 & 82 & 99 & 131 & $65-95$ & 67 \\
\hline Boys (7-8 years) & 153 & 36 & 47 & 56 & 68 & 89 & 65 & 70 \\
\hline Boys (9-13 years) & 351 & 41 & 54 & 65 & 79 & 103 & 73 & 66 \\
\hline Boys (14-18 years) & 352 & 47 & 61 & 74 & 89 & 116 & 95 & 82 \\
\hline Men (19-30 years) & 356 & 52 & 68 & 82 & 98 & 129 & 95 & 71 \\
\hline Men (31-50 years) & 348 & 55 & 72 & 87 & 105 & 137 & 95 & 62 \\
\hline Men (51-69 years) & 351 & 53 & 70 & 84 & 101 & 132 & 95 & 67 \\
\hline All women (7-69 years) & 1908 & 44 & 58 & 71 & 85 & 111 & $65-95$ & 84 \\
\hline Girls (7-8 years) & 151 & 36 & 47 & 56 & 67 & 87 & 65 & 71 \\
\hline Girls (9-13 years) & 352 & 38 & 50 & 59 & 71 & 92 & 73 & 78 \\
\hline Girls (14-18 years) & 354 & 40 & 53 & 63 & 75 & 97 & 95 & 94 \\
\hline Women (19-30 years) & 347 & 43 & 56 & 67 & 80 & 104 & 95 & 90 \\
\hline Women (31-50 years) & 351 & 47 & 61 & 73 & 87 & 112 & 95 & 84 \\
\hline Women (51-69 years) & 353 & 49 & 64 & 77 & 92 & 118 & 95 & 79 \\
\hline
\end{tabular}

Table 4. Estimated habitual total iodine intake from foods, iodised salt and supplements $(\mu \mathrm{g} / \mathrm{d})$ for Dutch men and women in several age categories and the proportion with a habitual intake below the estimated average requirement (EAR) or above the tolerable upper intake level (UL) (Dutch National Food Consumption Survey 2007-2010) (Medians and standard deviations)

\begin{tabular}{|c|c|c|c|c|c|c|c|c|c|c|c|c|c|c|c|c|c|}
\hline & \multicolumn{10}{|c|}{ Habitual total I intake $(\mu \mathrm{g} / \mathrm{d})$} & & \multirow[b]{3}{*}{ EAR } & & & \multirow[b]{3}{*}{ UL } & \multirow{2}{*}{\multicolumn{2}{|c|}{$\%>U L$}} \\
\hline & \multicolumn{3}{|c|}{ P5 } & \multicolumn{2}{|c|}{ P25 } & \multirow[b]{2}{*}{ Median } & \multirow[b]{2}{*}{ SD } & \multicolumn{2}{|l|}{ P75 } & \multicolumn{2}{|l|}{ P95 } & & \multicolumn{2}{|c|}{$\%<$ EAR } & & & \\
\hline & $n$ & Median & SD & Median & SD & & & Median & SD & Median & SD & & Median & SD & & Median & SD \\
\hline All men (7-69 years) & 1911 & 138 & 0.9 & 194 & 1.0 & 233 & $1 \cdot 3$ & 274 & 1.6 & 341 & $2 \cdot 2$ & $65-95$ & 1 & 0.0 & $300-600$ & 1 & 0.1 \\
\hline Boys (7-8 years) & 153 & 100 & 1.9 & 136 & 1.9 & 161 & $2 \cdot 2$ & 189 & $2 \cdot 6$ & 237 & $4 \cdot 0$ & 65 & 1 & 0.1 & 300 & 1 & 0.2 \\
\hline Boys (9-13 years) & 351 & 120 & 1.4 & 164 & $1 \cdot 3$ & 194 & 1.5 & 227 & 1.8 & 282 & $2 \cdot 8$ & 73 & 0 & 0.1 & $300-450$ & 2 & 0.2 \\
\hline Boys (14-18 years) & 352 & 137 & 1.6 & 189 & 1.6 & 223 & 1.8 & 257 & $2 \cdot 0$ & 315 & $2 \cdot 8$ & 95 & 1 & 0.1 & $450-600$ & 0 & 0.0 \\
\hline Men (19-30 years) & 356 & 144 & 1.4 & 202 & 1.4 & 240 & 1.6 & 278 & 1.8 & 341 & $2 \cdot 3$ & 95 & 1 & 0.1 & 600 & 0 & 0.0 \\
\hline Men (31-50 years) & 348 & 151 & 1.6 & 208 & $1 \cdot 8$ & 248 & $2 \cdot 0$ & 289 & $2 \cdot 2$ & 359 & 3.0 & 95 & 0 & 0.0 & 600 & 0 & 0.0 \\
\hline Men (51-69 years) & 351 & 145 & 1.4 & 196 & 1.6 & 232 & 1.8 & 270 & $2 \cdot 0$ & 333 & $2 \cdot 8$ & 95 & 0 & 0.0 & 600 & 0 & 0.0 \\
\hline All women (7-69 years) & 1908 & 117 & 0.6 & 158 & 0.6 & 188 & 0.8 & 219 & $1 \cdot 1$ & 277 & 1.7 & $65-95$ & 1 & 0.0 & $300-600$ & 0 & 0.1 \\
\hline Girls (7-8 years) & 151 & 98 & 1.6 & 129 & 1.8 & 150 & $2 \cdot 1$ & 172 & $2 \cdot 4$ & 209 & 3.1 & 65 & 0 & 0.0 & 300 & 0 & 0.1 \\
\hline Girls (9-13 years) & 352 & 106 & $1 \cdot 1$ & 141 & $1 \cdot 1$ & 164 & $1 \cdot 2$ & 189 & 1.5 & 229 & $2 \cdot 1$ & 73 & 1 & 0.1 & $300-450$ & 0 & 0.0 \\
\hline Girls (14-18 years) & 354 & 116 & 1.3 & 154 & 1.2 & 179 & 1.2 & 204 & 1.4 & 248 & 1.9 & 95 & 2 & 0.1 & $450-600$ & 0 & 0.1 \\
\hline Women (19-30 years) & 347 & 115 & 1.1 & 157 & $1 \cdot 2$ & 185 & 1.3 & 214 & 1.5 & 263 & $2 \cdot 2$ & 95 & 2 & 0.2 & 600 & 0 & 0.0 \\
\hline Women (31-50 years) & 351 & 117 & 1.0 & 160 & $1 \cdot 1$ & 191 & $1 \cdot 3$ & 223 & 1.5 & 284 & $2 \cdot 5$ & 95 & 2 & 0.1 & 600 & 0 & 0.0 \\
\hline Women (51-69 years) & 353 & 129 & 1.3 & 170 & 1.3 & 199 & 1.5 & 231 & 1.8 & 293 & 3.2 & 95 & 1 & 0.0 & 600 & 0 & 0.0 \\
\hline
\end{tabular}

milk-based drinks for children (12-16\%). Consumption of water contributed to about one-fourth of the I intake from non-alcoholic drinks. Diluted syrups and sodas had a high contribution for both children (50-58\%) and adults (23-31\%). For adults tea and coffee consumption also had a high contribution (37-40\%).

\section{Association with socio-demographic and lifestyle characteristics}

Among children, the intake of I from natural sources was positively associated with sex (male) and region (west), and negatively associated with age (low $v$. high) and educational level of the parents (low $v$. high, online Supplementary Tables S2 and S3). After correction for energy intake, the associations with sex and age disappeared. This means that the differences in I intake from natural sources between sex and age categories could be explained by the differences in energy intake. Children of low-educated parents had a $10 \%$ lower natural I intake compared with children of high-educated parents $(63 v .70 \mu \mathrm{g} / \mathrm{d})$. This may partly be explained by an approximately $20 \%$ higher intake of milk by children of high- $v$. low-educated parents $(330 v$ v. $396 \mathrm{~g} / \mathrm{d}$, online Supplementary Tables S6 and 7). Also, the proportion children not consuming milk was somewhat higher among children of middle-educated parents (30, 43, 27\%, respectively, low, middle and high; $P$ 0.02). Children living in the western region of the Netherlands had a $6 \%$ higher I intake compared with those living in the southern region $(68 v .64 \mu \mathrm{g} / \mathrm{d})$; again, this may be partly explained by a higher consumption of milk: west, 391; and south, $352 \mathrm{~g} / \mathrm{d}$. The regional proportion of children not consuming milk was similar to the distribution of children living in specific regions in the Netherlands (data not shown). 


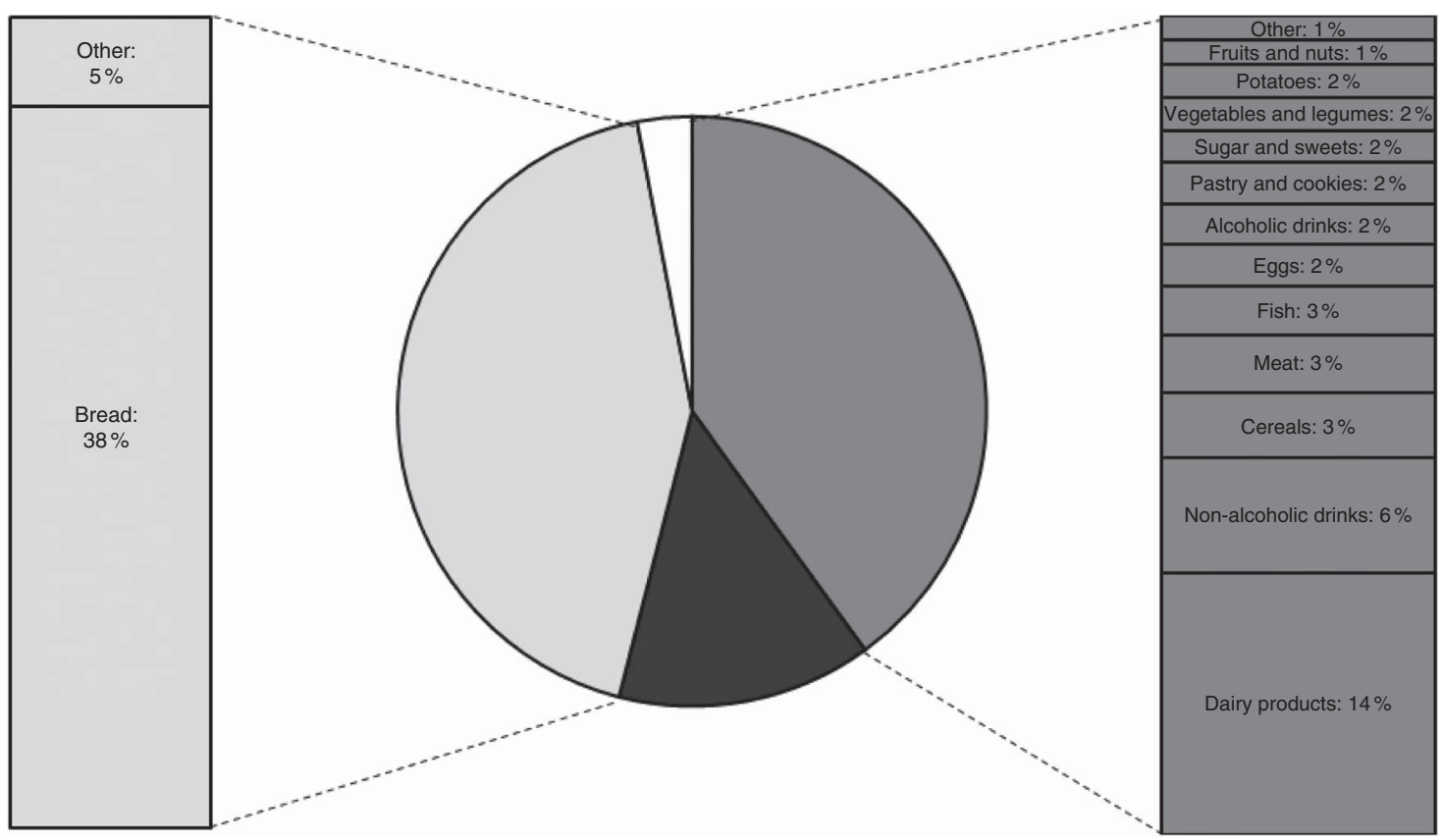

Fig. 2. Average contribution of different sources to the total iodine intake for the Dutch population aged 7-69 years (Dutch National Food Consumption Survey 2007-2010). $\square$, Naturally present 40 (sD 16)\%; $\square$, discretionarily iodised salt 14 (sD 12) \%; $\square$, manufacturer iodised salt 43 (sD 19) \%; $\square$, supplements 3 (SD 10) \%.

For adults, the intake of I from natural sources was associated with sex, age, educational level, region, season and income of the head of the household (online Supplementary Tables S2 and 3). After correction for energy intake, the associations with sex, age, region and educational level remained. In addition, an association with BMI appeared. In absolute quantities, the I intake was higher for males than females (88v. $77 \mu \mathrm{g} / \mathrm{d}$ ); however, relative to the energy intake, it was higher for females than males $(4.0 v 3.5 \mu \mathrm{g} / 418 \mathrm{~kJ}$ (100 kcal)). Similar to children, low-educated adults had a lower I intake compared with high-educated adults, which could partly be explained by an approximately $15 \%$ lower consumption of cheese (cheese: $46 v .53 \mathrm{~g} / \mathrm{d}$; online Supplementary Tables S6-S9) and a higher proportion of subjects not consuming cheese $(33,44,23 \%$, respectively, low, middle and high educational level; $P<0.0001)$. The average milk intake was similar between adults with different educational levels $(335,352,345 \mathrm{ml} / \mathrm{d}$ for, respectively, low, middle and high educational level; online Supplementary Tables S6-S9). However, the proportion of low- and middleeducated adults was higher among those not consuming milk compared with high-educated adults (36, 45, 19\%, respectively; $P<0 \cdot 0001$ ).

Among children, bread consumption, as proxy for the I intake from added iodised bakery salt, was associated with sex, age, BMI, income of the head of the household, education of the parents and season (online Supplementary Tables S4 and S5). After correction for energy intake, the associations with age, BMI, education of parents, and season remained. The older children (14-18 years, $144 \mathrm{~g} / \mathrm{d}$ ) consumed about 30\% more bread than younger children $(7-8$ years, $110 \mathrm{~g} / \mathrm{d}$ ); the largest part of this difference can be explained by an increased energy intake with age (data not shown). After correction for energy intake, bread consumption remained $8 \%$ higher (data not shown). For adults, bread consumption was associated with sex, BMI, income of the head of the household and region (online Supplementary Tables S4 and S5). After correction for energy intake, the associations with the income of the head of the household and region maintained.

\section{Discussion}

\section{Main results}

The estimated habitual total I intake seems adequate and safe (i.e. between the EAR and UL) for the largest part of the general Dutch population (7-69 years). I naturally present in foods (excluding iodised salt and supplements) contributed to about $40 \%$ of the total I intake, with dairy products and non-alcoholic drinks as the main sources. Another important source was iodised salt added by manufacturers ( $43 \%$ of the estimated habitual total I intake), of which bread consumption contributed about $90 \%$. Children of low-educated parents had a $10 \%$ lower I intake compared with children of high-educated parents, which is at least partly explained by a lower consumption of milk. In addition, these children consumed less bread, another important source of total I intake.

\section{Estimation of the iodine intake}

Measuring I excretion in a repeated 24-h urine sample in combination with statistical correction for within-person variation is the golden standard for I status ${ }^{(15-17)}$. However, this only gives an insight into the actual I intake, without information on the dietary 
pattern. Detailed food consumption surveys provide an insight into the intake of nutrients and also into the important sources of this nutrient in the dietary pattern. In simulation studies, data from food consumption surveys can be used to study the effect of potential changes (e.g. I policy or food composition) on the intake, a prior $i^{(19)}$. The total I intake is difficult to estimate from the Dutch food consumption surveys, similar to other consumption surveys, because of the several sources that are required to be taken into account and for some of which detailed data are lacking. Therefore, this study used a mathematical model, which is an improved version of an earlier model ${ }^{(18,19)}$. In contrast to the earlier model, the habitual total I intake distribution was estimated with a 'first shrink then add' approach instead of a 'first add then shrink' approach ${ }^{(24,27-31)}$. An advantage of this approach is that potential differences in model parameters for the several sources of total I intake - like within- and between-person variations, transformation - are retained in the modelling. In addition, it is possible to take into account source-specific information on nonusers (e.g. relevant for supplements and discretionary use of salt). All of these may influence the distribution and the evaluation of whether the intake is adequate or safe.

Further, detailed data on the use of iodised salt by manufacturers as well as discretionary use are lacking. Additional information was collected to overcome this issue; however, several assumptions had to be made as well. Food manufacturers (members of FNLI and NVB) provided data on the use of iodised salt in their products, and foods containing iodised salt as an ingredient were searched for in a commercial food database (www.innovadatabase.com). Altogether, this gives a more or less complete image of the use of iodised salt by manufacturers of foods available on the Dutch market. This inventory showed that the use of iodised salt by manufacturers is limited, except for bread and, to a lesser extent, pizza. On the basis of this information, assumptions regarding the market share of products within food groups containing iodised salt were decreased compared with earlier assumptions. For the I policy change in 2008 it was assumed that $50 \%$ of the foods, other than bread, would be prepared with iodised salt ${ }^{(14)}$; our study showed that in 2012 this was a large overestimation. Consequently, the proposed population I intake could not be obtained. In addition, the 5\% assumed in later scenario studies seemed already an overestimation ${ }^{(18,19)}$. Iodised salt is added to a limited part of the food groups, with a limited market share.

Information on the discretionary use of salt was collected in the 3rd year of data collection of DNFCS 2007-2010; the age and sex-specific proportion of subjects using discretionarily iodised salt was applied to the data of the 1st and 2nd year of data collection. This only provided information on whether subjects were using discretionarily iodised salt; it was not known in what foods and in what amount. On the basis of other studies, assumptions were made. For better estimation of the I intake, it is important to collect detailed information on the discretionary use of iodised salt: for what foods or dishes it is used, what amounts are added, and in line with that, how much is retained in the food consumed.

Similar to the earlier model ${ }^{(18,19)}$, the results of our modelling exercise were compared with the I intake estimated from single 24-h urine samples in the Doetinchem Cohort Study, a town in the eastern part of the Netherlands ${ }^{(13)}$ (data not shown). The I intakes estimated in our study were somewhat higher, but in the same order of magnitude, compared with the I intake estimated from urine samples. This indicates that the calculation model is good to estimate the I intake. The differences may be due to the several assumptions in the mathematical model, but also to differences between the populations in both studies, for example, national representative $v$. one city, age distribution.

\section{lodine concentration in food and supplements}

Similar to food composition tables in other countries, the Dutch food composition database contains nutrient information from chemical analyses, but also information from, for example, foreign databases, recipe calculations and label information. For our study, the I concentration data were updated, compared with earlier studies ${ }^{(18,19)}$; however, continuous updates are required to maintain good data quality. The I content of food depends on the I content in soil and feed; therefore, large differences may appear within food groups produced in different places in the world. The impact of this on the Dutch food supply is unclear. Recent studies from UK show that organic milk has lower I concentrations than conventional milk, and that winter milk contains higher I concentration compared with summer milk ${ }^{(32,33)}$. For bread, there may also be a difference in I content between organic and conventional; because of a court decision, the addition of iodised bakery salt is not mandatory in the Netherlands. However, via a covenant between the Dutch Ministry of Health and manufacturers of conventional bread, the use of iodised bakery salt is encouraged, resulting in virtually all conventional fresh bread being baked with iodised bakery salt. Organic and imported breads (e.g. partially baked bread segment) are not included in this covenant. As a consequence, not all organic bread and imported bread contain iodised bakery salt. This may implicate that subjects consuming organic foods may be at risk of inadequate I intakes. The organic food market is growing in the Netherlands ${ }^{(34)}$. As such, the number of subjects consuming bread without iodised bakery salt may increase. Unfortunately, from the DNFCS 2007-2010, it is not clear who consumed organic foods. It is important to get a better insight into the consumption pattern of those consuming organic foods, as well as into the range of I concentrations within food groups, especially between organic and conventional foods. Another important issue is the worldwide effort to reduce salt intake; as fortification with $\mathrm{I}$ is mainly via iodisation of salt, reduction of salt intake may influence the I intake ${ }^{(35-38)}$. To maintain adequate I intake, it may be required to increase salt I levels or search for other ways to elevate the I intake and/or content of foods in a safe way.

The information on the label was used for the composition information of dietary supplements. Italian research showed that part of the I-containing supplements contained higher levels than declared ${ }^{(39)}$. It is unknown how well the label information regarding I content of supplements in the Netherlands predicts the actual concentration. The use of I-containing supplements is rather low in our population (about 
$10 \%)$ and the potential effect of underestimation or overestimation is expected to be limited. To improve the nutrient estimations, it is recommended to study the actual nutrient content, including I, of supplements.

\section{Comparison with other research}

I intake in the Netherlands depends largely on the I policy. This policy changed in 2008. It is therefore impossible to check the validity of our calculation model with studies on I intake in the Netherlands before 2008. Further, international differences in I policy also influence the interpretation of comparisons of I intake between countries. The results of the 24-h urine sample study were used to validate the mathematical models; it is therefore expected that our study also shows a reduced I intake compared with earlier estimations ${ }^{(18)}$. The effects of a changing I policy ${ }^{(10)}$ mainly cause this reduction. In this policy, the I concentration for bread was reduced in order to maintain safe I intakes when a much larger part of the food supply (50\%) would contain iodised salt. As explained earlier, this assumption appeared to be an overestimation of the situation in 2012.

Similar to our study, dairy products were an important I source in Iceland ${ }^{(40)}$ and Norway ${ }^{(41)}$, and non-alcoholic beverages in Germany ${ }^{(42)}$. Because of the Dutch I policy, most of the bread contains iodised bakery salt, which has a higher I level than do other foods and household salt. This makes bread an important source of I in the Netherlands. Also, in some other countries, bread with iodised salt is used as vehicle to increase I intake ${ }^{(43-46)}$. In the Netherlands, for a long time, I intake was considered adequate, but transferring the Dutch I policy to other countries will not always result in adequate I intakes, because of differences in food habits. This is also important to consider in the ongoing EU harmonisation for addition of vitamins and minerals to foods ${ }^{(47)}-$ especially for I, a nutrient for which many countries rely on addition to food to get a population with adequate intakes.

\section{Implications for research}

There are several methodological challenges in the estimation of the habitual I intake and its sources. For I, similar to other nutrients like $\mathrm{Na}$, more information is required than currently present in food consumption surveys. Some suggestions for improvement of data collection will be presented. First, if there is a mixture of foods within a product category being or not being produced with iodised salt, it is important to know which food was consumed exactly and whether this was produced with iodised salt. In addition, the composition of these foods should be available. Second, information on discretionary use of iodised salt is required. The 24-h recall (or other methods) could be expanded with specific questions on whether iodised salt was used during meal preparation or consumption so that information can be gathered on specific food groups. Third, an additional requirement is knowledge on the amounts of iodised salt discretionarily added and the retention during meal preparation. It is very difficult, perhaps impossible, to ask subjects to quantify how much salt they added. Additional research chemically measuring the amount of I in food after a normal meal preparation would probably give a more reliable result. However, people are aware of the advice to restrict salt, which may influence the results if subjects know the topic of research. Further, to get an insight into the variation of addition of salt, it is important to conduct this research in a large group, preferably representative of the population. Fourth, to validate a calculation model, information from a golden standard is required. It is best to have both available from the same subjects in the same time period.

\section{Conclusions}

The I intake of the general population in the Netherlands, aged 7-69 years, seems adequate, although lower compared with that during the period before 2008. Our study did not include all age groups, and no pregnant or lactating women; conclusions on adequacy may not be valid for those groups. The same is true for subjects with thyroid-related diseases. Iodised bakery salt added to bread, as well as dairy products and non-alcoholic drinks, are important sources of I. With the current effort to reduce the salt intake and changing dietary patterns (i.e. less bread, more organic foods) it is important to keep a close track on the I status, important sources and potential risk groups, and, when needed, to adapt the I policy in order to maintain adequacy of the I intake in the Netherlands.

\section{Acknowledgements}

The authors would like to thank Christine Grit (FNLI) and Willemien Mussche-van Andel (NVB) for their help with the inventory regarding the use of iodised salt by the members of their organisations. Further, the authors would like to thank Heidi Fransen (National Institute for Public Health and the Environment (RIVM)) for statistical support, Martine Jansen-van der Vliet and Agnes Roos (both RIVM) for help with the food composition data and Zohreh Ghameshlou (RIVM) for data management support.

The present study was funded by the Netherlands Ministry of Health, Welfare and Sports. The Netherlands Ministry of Health, Welfare and Sports had no role in the design, analysis, interpretation or writing of this article.

J. V.-K. and C. T. M. v. R. initiated the study. C. T. M. v. R. provided the data. J. V.-K. and E. J. M. B.-R. were involved in the analyses. A. L. M. D. developed SPADE and provided assistance with the analyses. J. V.-K. prepared the first draft of the manuscript, which was critically evaluated and refined by C. T. M. v. R., E. J. M. B.-R. and A. L. M. D. and J. V.-K. prepared the final draft of the manuscript.

None of the authors has any conflicts of interest to declare.

\section{Supplementary material}

For supplementary material/s referred to in this article, please visit https://doi.org/10.1017/S0007114517000733 


\section{References}

1. Andersson M, De Benoist B, Darnton-Hill I, et al. (2007) Iodine Deficiency in Europe: A Continuing Public Health Problem. Geneva: WHO.

2. Scientific Committee on Food, Scientific Panel on Dietetic Products Nutrition and Allergies (2006) Tolerable Upper Intake Levels for Vitamins and Minerals. Parma: European Food Safety Authority.

3. de Benoist B, McLean E, Andersson M, et al. (2008) Iodine deficiency in 2007: global progress since 2003. Food Nutr Bull 29, 195-202.

4. Health Council of the Netherlands (2008) Towards Maintaining An Optimum Iodine Intake. The Hague: Health Council of the Netherlands.

5. Anonymous (2008) Convenant gebruik bakkerszout (Covenant use bakery salt). Staatscourant 209, 1-3.

6. van Rees-Wortelboer MM, Schroder-van der Elst JP, Lycklama A, et al. (1987) Iodine and goiter in The Netherlands. Ned Tijdschr Geneeskd 131, 1821-1824.

7. Anonymous (1998) Warenwetregeling vrijstelling jodering keuken - en broodzout (Commodity act regulation exemption iodization of kitchen salt and bread salt). Staatscourant 62, 15 .

8. Anonymous (1999) Intrekking Warenwetregeling vrijstelling jodering keuken- en broodzout (Withdrawal of Commodity act regulation exemption iodization of kitchen salt and bread salt). Staatscourant 51, 5 .

9. Anonymous (1996) Besluit van 24 mei 1996, houdende het warenwetbesluit Toevoeging micro-voedingsstoffen aan levensmiddelen (Decision of 24 May 1996, Commodity Act decision addition of micronutrients to foods). Staatsblad $\mathbf{3 1 1}$, $1-18$.

10. Anonymous (2008) Besluit van 13 juni 2008, houdende wijziging van het Warenwetbesluit Toevoeging microvoedingsstoffen aan levensmiddelen, inzake het toevoegen van jodium (Decision of 13 June 2008, change of Commodity Act decision Addition of Micronutrients to foods, concerning the addition of iodine). Staatsblad van het Koninkrijk der Nederlanden 257, 1-5.

11. Anonymous (2005) Judgment of the Court of 2 December 2004 in case C-41/02. Official J Euro Union C19, 1.

12. Rigter RBM (1992) Met raad en daad. De geschiedenis van de gezondheidsraad 1902-1985 (Assist and advide. The history of the Health Council of the Netherlands 1902-1985). PhD, Erasmus University Rotterdam (in Dutch), Rotterdam.

13. Hendriksen MA, van Raaij JM, Geleijnse JM, et al. (2014) Monitoring salt and iodine intakes in Dutch adults between 2006 and 2010 using $24 \mathrm{~h}$ urinary sodium and iodine excretions. Public Health Nutr 17, 1431-1438.

14. Kruizinga AG, Doest D, Brants HAM, et al. (2006) De jodiumvoorziening in Nederland op basis van databestanden van de voedselconsumptiepeilingen (The iodine supply in the Netherlands based on data of the Dutch Food Consumption Surveys). No. V7049. Zeist: TNO.

15. World Health Organization, United Nations International Children's Emergency Fund \& International Council for Control of Iodine Deficiency Disorders (2007) Assessment of Iodine Deficiency Disorders and Monitoring Their Elimination. A Guide for Programme Managers. Geneva: WHO.

16. Zimmermann MB \& Andersson M (2012) Assessment of iodine nutrition in populations: past, present, and future. Nutr Rev 70, 553-570.

17. Rohner F, Zimmermann M, Jooste P, et al. (2014) Biomarkers of nutrition for development - iodine review. J Nutr $\mathbf{1 4 4}$ 1322S-1342S
18. Verkaik-Kloosterman J, van 't Veer P \& Ocke MC (2009) Simulation model accurately estimates total dietary iodine intake. J Nutr 139, 1419-1425.

19. Verkaik-Kloosterman J, van 't Veer P \& Ocke MC (2010) Reduction of salt: will iodine intake remain adequate in The Netherlands? Br J Nutr 104, 1712-1718.

20. Institute of Medicine (2001) Dietary Reference Intakes for Vitamin A, Vitamin K, Arsenic, Boron, Chromium, Copper, Iodine, Iron, Manganese, Molybdenum, Nickel, Silicon, Vanadium, and Zinc. Washington, DC: National Academies Press.

21. Van Rossum CTM, Fransen HP, Verkaik-Kloosterman J, et al. (2011) Dutch National Food Consumption Survey 20072010. Diet of Children and Adults Aged 7 to 69 Years, no. 350050006/2011. Bilthoven: RIVM.

22. National Institute for Public Health and the Environment (2011) NEVO-tabel. Nederlands Voedingsstoffenbestand 2011 (NEVO-table. Dutch Food Composition Database 2011). Den Haag: RIVM. http://www.rivm.nl/en/Topics/D/ Dutch_Food_Composition_Database

23. Buurma-Rethans E, Fransen H, Ghameshlou Z, et al. (2008) Een databestand voor supplementen: behoeftes en acties (Data file for supplements: needs and actions). Voeding $N u$, 10, pp. 21-24.

24. Dekkers AL, Verkaik-Kloosterman J, van Rossum CT, et al. (2014) SPADE, a new statistical program to estimate habitual dietary intake from multiple food sources and dietary supplements. J Nutr 144, 2083-2091.

25. Hendriksen MAH, Wilson-Van den Hooven EC \& Van der A DL (2011) Zout- en jodiuminname 2010. Voedingsstatusonderzoek bij volwassenen uit Doetinchem (Salt and iodine intake 2010. Nutritional status study among adults in Doetinchem). RIVM rapport no. 350070004. Bilthoven: RIVM.

26. Huybrechts I, Lin Y, De Keyzer W, et al. (2011) Dietary sources and sociodemographic and economic factors affecting vitamin D and calcium intakes in Flemish preschoolers. EurJ Clin Nutr 65, 1039-1047.

27. Verkaik-Kloosterman J, Dodd KW, Dekkers AL, et al. (2011) A three-part, mixed-effects model to estimate the habitual total vitamin D intake distribution from food and dietary supplements in Dutch young children. J Nutr 141, 2055-2063

28. Dodd KW, Bailey R, Wilger J, et al. (2009) Estimating distributions of usual total nutrient intake: a comparison of available methods, p. 131. 7th International Conference on Diet and Activity Methods. ICDAM.

29. Garriguet D (2009) Challenges in combining food and supplement intake data using the Canadian Community Health Survey - Nutrition, p. 132. 7th International Conference on Diet and Activity Methods. ICDAM.

30. Garriguet D (2010) Combining nutrient intake from food/ beverages and vitamin/mineral supplements. Health Rep $\mathbf{2 1}$, $71-84$.

31. van der Voet H, de Mul A \& van Klaveren JD (2007) A probabilistic model for simultaneous exposure to multiple compounds from food and its use for risk-benefit assessment. Food Chem Toxicol 45, 1496-1506.

32. Bath SC, Button S \& Rayman MP (2012) Iodine concentration of organic and conventional milk: implications for iodine intake. Br J Nutr 107, 935-940.

33. Payling LM, Juniper DT, Drake C, et al. (2015) Effect of milk type and processing on iodine concentration of organic and conventional winter milk at retail: implications for nutrition. Food Chem 178, 327-330.

34. Logatcheva K (2015) Monitor Duurzaam Voedsel 2014. Consumentenbestedingen. Wageningen: LEI. 
35. Anonymous (2009) National salt initiatives: implementing the EU framework for salt reduction initiatives. http://ec.europa.eu/ health/archive/ph_determinants/life_style/nutrition/documents/ national_salt_en.pdf

36. Appel LJ (2006) Salt reduction in the United States. BMJ 333, 561-562.

37. Directorate General Health and Consumers (2012) Implementation of the EU salt reduction framework. Results of Member States survey. Luxembourg: Publication Office of the European Union.

38. Food Standards Agency (2006) Salt reduction targets 2006. http://webarchive.nationalarchives.gov.uk/20120206100416/ http://food.gov.uk/news/newsarchive/2006/mar/salttargets (accessed April 2017).

39. Restani P, Persico A, Ballabio C, et al. (2008) Analysis of food supplements containing iodine: a survey of Italian market. Clin Toxicol (Phila) 46, 282-286.

40. Gunnarsdottir I, Gustavsdottir AG \& Thorsdottir I (2009) Iodine intake and status in Iceland through a period of 60 years. Food Nutr Res 53, 10.3402/fnr.v53i0.1925.

41. Dahl L, Johansson L, Julshamn K, et al. (2004) The iodine content of Norwegian foods and diets. Public Health Nutr 7, 569-576.

42. Johner SA, Gunther AL \& Remer T (2011) Current trends of 24-h urinary iodine excretion in German schoolchildren and the importance of iodised salt in processed foods. Br J Nutr 106, 1749-1756.

43. Schiess S, Cressey PJ \& Thomson BM (2012) Predictive modelling of interventions to improve iodine intake in New Zealand. Public Health Nutr 15, 1932-1940.

44. Moreno-Reyes R, Van Oyen H \& Vandevijvere S (2011) Optimization of iodine intake in Belgium. Ann Endocrinol (Paris) 72, 158-161.

45. Rasmussen LB, Ovesen L, Christensen T, et al. (2007) Iodine content in bread and salt in Denmark after iodization and the influence on iodine intake. Int J Food Sci Nutr 58, 231-239.

46. Rasmussen LB, Jorgensen T, Perrild H, et al. (2014) Mandatory iodine fortification of bread and salt increases iodine excretion in adults in Denmark - a 11-year follow-up study. Clin Nutr 33, 1033-1040.

47. Anonymous (2007) Orientation paper on the setting of maximum and minimum amounts for vitamins and minerals in foodstuffs. Brussels: European Commission Health \& Consumer Protection Directorate-General.

48. CPB Netherlands Bureau for Economic Policy Analysis (2015) Macro Economic Outlook (MEV) 2016 [in Dutch]. http://www. cpb.nl/publicatie/macro-economische-verkenning-mev-2016 (accessed April 2017). 